\title{
DILUIÇÃO DO SEMEN DE BOVINO EM LEITE DESNATADO EM PÓ
}

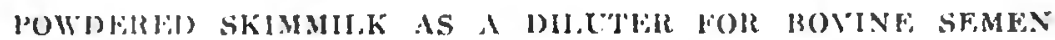

\author{
Jỗo SOARES VFIGA \\ Professor \\ Ló: Masotti \\ Assistente
}

\author{
Armando Cinlefri \\ Assistente, D.l. \\ Josf́: DF. Assis RibejRo \\ Assistenle
}

Desde que se vishumbraram as imensas possibilidades oferecidas pelo método de inseminação arlificial, intensificaram-sc os esludos sōbre os diluidores de sémen, como meio não só necessário para aumentar o número de doses para inseminação, como para preservação e aumcnto da fertilidade do material fecundante. Da numerosa variedade de meios diluidores preconizados, restou, para os serviços de rolina, como o mais recomendável, quer pela eficiência, quer pela simplicidade de sel preparo, o meio diluidor jdeado por Philcups e LARDY, composto de uma soluçăo de citrato de sódio, nisturada com gema de ovo fresco. fsecs mesmos autores experimentaram diluix o sêmen de hovino em leite evaporado, mas obtiveram resultados inferiores aos obtidos com diluidor gemaritrato.

() interêsse $\mathrm{em}$ se descubrircm novos meios diluidores prosseguiu. e continua, dadas as dificuldades por vezes encontradas, nos centros de inseminaçäo artificial, em se obterem ovos rigorosamente frescos, no preparo c na esterili. zaçāo do material.

Os estudos sôbre o emprêgo do leite de vaca como diluidor foram, ao que parece, iniciados por Hoffmann ("in" CARBuntro), logo a seguir inexplicàvelmente abandonados. Em 1950, Michajllov, na (hecoslováquia, oferece indicaçöes precisas sôbre o enprêgo dêsse prodıto como diluidor do sêmen de animais, utilizando-o depois de fervido, filtrado e resfriado.

De acôrdo com as observaçôes de Thíker e Aimquist. os leites homcge. neizado e desnatado. uma vez fervidos, evidenciaram manter, em condições sa. tisfatórias, a motilidade dos espermatozioides do sêmen diluido, an mesmo tempo que. nesses mesmos leites nāo fervidos, a conservação se fazia em condiçōes b'm inferiores.

Fsses mesmos autores verificaram que o sêmen diluido em leite homogenei. zado fervido, sem adição de antibióticos, apresentava porcentagens de fertilização 
ligeiramente superiores às do sêmen diluido em gema-citrato, nas experiências de campo.

Dentre as conclusōes a que chegaram, ressaltam aquêles $A$.. as que ste riaferem à necessidade de se elevar a temperatura do leite a $95^{\circ} \mathrm{C}$ de 1 a $10 \mathrm{mi}$ nutos, de preferência lentamente, a fim de que, com esta temperatura, se proceksem modificaçōes químicas ou físicas no lẹte, modificaçöes essas que permi. tem aos espermatozóides sobreviverem até 16 dias nesse meio. A diluição do sêmen em leite não fervido, emhora pasteurizado, evidenciou péssimos resultados. visto que os espermatozóides apresentavarn fraca molilidade. já com dois dias de conservação.

Outros pesquisadores se dedicaram ao mesmo assunto (STrassbi RG, 19.52; JacQlet e (Assot, 1952; SafFIIE; 1952).

Jicplict e Cassor: voltaram suas atengôes para o leite desnatado em pin, em face das dificuldades encontradas na falıa de padronização dos leiles co. muns desnatados, líquidos encontrados no comércio. fisses AA. juntam, ao leite em pú, antihióticos em doses convenientes e assim o remetem aos centros de in* minação. Para preparar o diluidor leite em pó com antibiólicos, é êle diluido em 10 partes de seu volume en água bidistilada, para depois ser incluido na proporção de $10 \%$ en gema de ovo.

A técnica de Jacquet e Cassou, pois, näo indica a fervura do leite e recomenda ainda a juclusāo de grema de ovo. Todos os AA. citados sāo unânimes em evidenciar a vantagem do emprêgo do leite desnatado sôhre o leite integral, em vista das dificuldades que êste último demonstra, to exame microscópico, em virtude dos glóbulos de gordura que contém.

Para nossas pesquisas empregamos leite desilatado em po, encontrado no comércio para fins dietéticos, com as seguintes caracteristicas: produto obtido do leite fresco, previamente pasteurizado e pulverizado pelo "spray-drying", apresentarido a seguinte composição:

\begin{tabular}{|c|c|c|}
\hline Gordural & 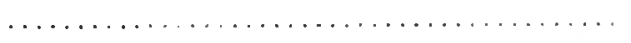 & $1,8 \%$ \\
\hline P'rotrinas & 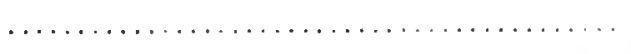 & $38,0 \%$ \\
\hline 1.actose & & $\bar{s}\left(1, z^{2}+s\right.$ \\
\hline Sinis minerais & & $7,5 \%$ \\
\hline Lmidade & $\ldots$ & $3, \mathrm{t}^{\prime} \mathrm{n}$ \\
\hline
\end{tabular}

MATERIAL, F, MEIOI)(

As anıostras de sêmen estudadas provieram de trếs louros da la; a Holandesa, variedade preta c branca, que servem no Pôsto de Inseminaçäo Artificial 
da Faculdade de Medicina Veterinária da Liniversidade de São Paulo (PIArt.). 0 método empregado para a obtenção do material foi o da vagina artificial, cuja técnica $\dot{c}$ bem conhecida, comando-se todos os cuidados comuns. Após a obtenção, o material foi examinado em gôla pendente, recebendo classificaçóes de acôrdo com a densidade e a molilidade devidamente anotadas em fichas. A prova de redução do azul de metileno foi -empre efeluada, nas diferentes fuses da experiência $\mathrm{cm}$ que se loruou necessária.

0) diluidor foi preparado, em linhas gerais. scegundo a técnica de Michas. I.ov. O leite desnalado em pó foi pesado a submelido à reconstituição em água bidistilada esterilizada, na razão de $1: R$. Depois de perfeitamente homogeneizado, foi filtrado e fervido, por quatro vexes, em chama de làmpada de álcool. () produto, noramente filtrado, recebeil antibiúticos $\mathrm{cm}$ dosagen adequada (até mil unidades de penicilina e estreptomicins por $\mathrm{cm}^{3}$ l. Após a reconstituição do leite, verificanos o pll com indicador universal, assinalando-se um valor entre 5 a 6. O) teile loi conservado em geladeira a temperalura de $5^{\circ} \mathrm{C}$. Amostras submelidas a prosa de identificaçäo de numero de germens revelaram-se estéreis em caldo simples ec cm agar simples.

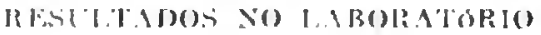

Colhido, canaluado a julgado o sêmen pelas prosas acima ciladas, foram feitas as diluiçós lenlamente, mantendo a temperatura a $37^{\circ} \mathrm{C}$, na base de $1: 4$, l: $:$ e $1:] 0$. As amostras. diluidas c mantidas em geladeira a 5 "C, foram sub. metidas a evames periudicos em gota pendente e pela redução do azul de metileno. Fas amostras foram comparadas com amostras de sêmen da mesma colheita diluido en gema-citrato, consideradas testernunhas. Pesquisamos, em algumas amostras, porcenlagem de espermaiozóides viros e mortos, através a coloração vital pela cosina e nigrosina ( $\mathrm{Sw}$ trsov e BEARnrivi, eleluando, também, o necessário contrôle rom amostras tesirmunhas.

As amostras de sêmen-leite desnatado em pó e de sêmentgema-ritrato, sob - contrôle bacteriolúgico, demonstraram crescimento aproximado de 120 a 100 colônias de germens por $\mathrm{cm}^{3}$, respectivamente.

Os primeiros resultados obtidos demonstraram ser possivel a utilização do leite desnatado em pó, como diluidor para sêmen de bovino, pois o sêmen assim tratado se comportou, no laboratório, de maneira semelhante à do sêmen diluido em gema-citrato. As provas de conservaçäo foran satisfalórias, tendo-se mantido uma amostra, nas condiçôes usuais, até 288 horas, quando recebeu a nota 1 no exame para motilidade. 


\section{RFSLITIDO DAS INSFIINASOR}

Sêmen diluido na proporção de $1: 4=1: 10 \mathrm{~cm}$ leite em pi, reconsituido. foi distribuido a diversos criadores e Departomentos oficiais, para verificação do poder fecundante. O transporte dêste material foi efetuado segundo a ticnica normalmente utilizada pelo Pôsto de Inseminação Artificial da Faculdade de Me. dicina Veterinária dä Universidade de São Paulo, que consiste en se acondicionarem os tubos de sêmen diluido, de capacidade pouco superior a $3 \mathrm{~cm}^{3}$, ao redor de latas contendo água congelada; envolver essas latas em envelopes de papel grosso e, finalmente, mantê-las dentro de diuas caixas de papelão, empregando como substancia isolante, papel de jornal picado. Fissas caixas são enviadas de São Paulo e atingem seu destino por meio de ônibus. caninhões, etc., num lapa-o de tempo que varia de 2 a 8 horas.

Nos pontos de recepção, os lubos de sêmen são retirados das caixas e mais. tidos em geladeira cntre 5 e 10 ' $\mathrm{C}$ ate o momento da inseninação. Os postos redistribuidores enviam amostras às fazendas, ac'ondicionando-as nas mesmas caixas.

O sistema de contrôle das porcentagens de fecundação obtidas pelo PIArt da Faculdade de Medicina Veterinária encontra sirios ohsticulos. pelos seguintes motivos:

a) os criałorcs recétem o material do Pôsto e o utilizam. fazentio a rece. cessária comunicação, mensalmente. Fsses dados são anotalos em fichas e-jueciais:

b) periòdicamente, un encarregado du Serviço visita as fazendas para fazer os diagnóaticos de gestação nas varas inseminadas;

c) cutretanto, fogem ao contrōle do l'ôsto, o movimento de vendas cie animais inseminados antes do diagnóstico; o estado sanitario do rehanho. princi. palmente no que se refere à esfera genital; a conservapăa do sêmen depois da expedição e a inseminaçăo propriamente dita.

Qualquer tenlativa, portanto, para se ralcular o indice de fecundação sôlire as vacas que não retornam à inseminação, considerando-a: fecundadas, como nô. malmentc se faz, is succetivel de resultados falsos.

Por lal motivo, resolvemos incluir, nos nossos resultados, apenas as valla: que efetivamente produziram bezerros de inseminação artificial, nascimentos êsse. nảo só conunicados pelos criadores, como observados pelo Serviço. Esses ialdos, tomados após os nascimentos dos produtos, são os mais correlos e, natural. mente, oferecem porcentagers menores do que quando se consideram os "nitu retornos" à inseminação, após 40 ou 60 dias.

A fim de não lançar um produto no meio criador, abruptamente, sem co. nhecê-lo suficientemente, embora as provas de laboratorio fóssem as mais satis- 
fatorias possiveis, cmiamos. 110 periodo ds 9 de abril a 12 de novembro de 1953. apenas algumas doses de sêmen diluito em leite desnalado em pó, sêmen ram que foi aplicado puramente ao acaso, sem seleção ou escolha de vacas a inseminar.

Vessas circunstancias foram efetuadas, tm propriedades diferentes, 81 inseminaçöes rom sêmen diluido em leite desnatado em pó. das quais se verificarar 51 nascimentos. Tais resultados oferecem a porcentagem de $60,71 \%$ de fecundaçăo. ou seja 1.61 inseminaçōes por produlo nascido.

Para 50:3 nasrimentos provenientes de inseminações com sêmen diluido em gema-citralo foram necessúrias 1.09 t insentnaçōes, ou sejam $15.97 \%$ ou ainda 2.17 inmeminações por produto nascido.

Es:a diferença e bem superior a verificada por Thacker e Almptist que. calculando as porecnlagens na hase do "lläo retôno" dentro de 60 a 90 dias, encontraram $72,7 \%$ e $71,4 \%$, respectivam mogeneizado esimen diluido em gema-citratu.

(1) resultados, portanto, parectem fasorecer francamente o sênicn diluido em leite "'m pí desnatado devidamente reconslibuido.

() PIAıl da Faculdade de Medicina Veterinária está iniciando a remessa sistematica do novo material para verificaçä mais ampla.

De qualquer maneira. o simples falo d:: näo se terem verificado resultados inferinges ans conseguidos pelo sêmen diluiılo $\mathrm{cm}$ gema-citralo, parece recomendar a diluiçáo do sêmen em lente en po desnatado. pelas santagens que oferece mo so u preparo e: que podem ser assim resumidas:

a) ntilizaçän de um material padroniaado cm sua composiçāo;

b) Sacilidade de esterilizaçāo:

c) couservagă quase indefinida do leile em pio devidamente acondicionado;

d) possibilidade de conservação do diluidor reconstitudo, em geladeira, duratite longo tempo:

e) rapidez no prejuro;

f) baixo custo de obtençäo;

g I facilidade de aquișigão.

\section{1..ती}

A lim de verificar a possibilidade de empregar o leite desnatado em pó como meio diluidor para sêmen de bovino, laram realizados estudos de labora- 
tório e de campo. Os primeiros, para avaliar a capacidade do diluidor em manter vivos os espermatozóides por tempo considerado satisfatório. Os segundos. para julgar a capacidade fertilizante do material.

O leite desnatado em pó foi adquirido no comércio com as seguintes características: produto obtido do leite fresco, prèviamente pasteurizado e pulverizado pelo "spray-drying", apresentando a seguinte composição:

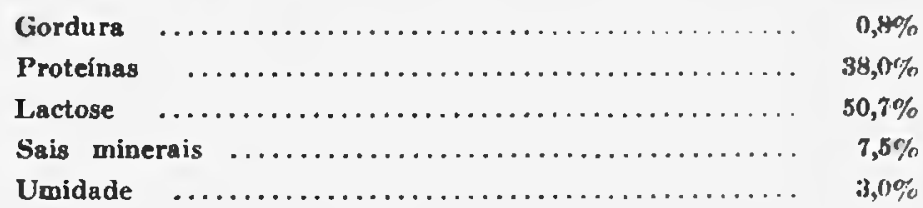

A técnica de preparo seguida foi a seguinte:

a) diluição do leite em pó na proporção de I para 8 de água lididistilada esterilizada;

b) filtração em papel de filtro;

c) aquecimento até levantamento da fervura por quatro vezes;

d) nova filtração;

e) resfriamento;

f) adiçāo de antibióticos;

g) diluição do sêmen à temperatura de $37^{\circ} \mathrm{C}$.

Os resultados de laboratório obtidos foram considerados plenamente satis. fatórios, quando comparados com os do diluidor gema-citrato.

De 84 inseminações realizadas com sêmen diluido em leite desnatado em pó verificaram-se 51 nascimentos $(60,71 \%)$. Para 503 nascimentos provenientes de sêmen diluido em gema-citrato, ioram necessárias 1.094 inseminaçóes $(45.97 \%)$. Tais resultados parecem indicar possibilidades para o diluidor leite em pó desnatado, especialmente quando se consideram os seguintes pontos:

a) utilização de um material padronizado em sua composição;

b) facilidade de esterilização;

c) conservação quase indefinida do leite em pó devidamente acondicionado;

d) possibilidade de conservação do diluidor reconstituido, em geladeira, durante longo tempo; 

e) rapidez no preparo;
f) baixo custo de obtenção;
g) facilidade de aquisição.

\section{MBSTRACI}

Iahoratory and field experiments were conducted to study the use of powdered shimmilk as a diluter for bovine semen.

Commercial powdered skimmilk used in these experiments had the specifications as follows: The technique carried out to prepare the skimmilk dilutor was: a) dilution of powdered skimmilk in bi-distiled uater $(1: 8)$; b) filtration after stitting; c) heating till boilling fous times; d) filtration; e) cooling; f) addilion of antibiotiques (penicillin and streptomycin); g) dilution of senen at $37^{\circ} \mathrm{C}$ of temprerature.

In laboratory test the skinmilk diluter compared as satisfactory as ylokcitrate diluter.

On the basis of 84 inseminations with diluted semen on skimnilk diluter 51 calves were born $(60.71 \%)$. I or semen diluter in yolk-cirate 503 calves resulted from 1.094 inseminations $(45.97 \%)$.

Based upon satisfactory results it appears that the poidered skimmilk of. fers a convenient diluter for semen mainly due: a) a even composition; b facility to sterilize; c) the powdered skimmilk can be kept for long time without damage; d) the diluter can be preserved at low temperature for long time; e) it is easy to prepare and there are facilities to buy for low prices.

\section{REFERTNOAS BIBLIOGRAFICAS}

Canbonego, D. - 1944 - Fecundución Arlificial: 2i23, Madrid, J. I'ucyo

Jaceozt, J. - Caszoc, R. - 1952 - Ninuvelles recherches sur un milieu à base de lait erremó en vue de la dilution et de la conservation du sperma de trureaux. Bull. Arad. Fil. France, $25(4): 149 / 56$

Michajiot, N. N. - 1950 - Sperm dilution in the milk. The Czechosloz'uh Vet. Mag., "in" J.A.V.H.A., $117(8333): 3337$

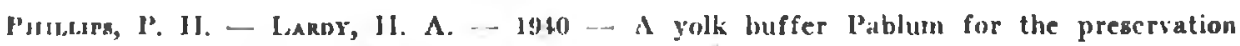
of bull Semen. J. Dairy Ssci, $23: 399 / 404$

SAnfile, V. - 1952 - 11 latte como diluitore del liquido seminale. Zooprofilassi, MiIano, $6(11): 523 / 5$ 


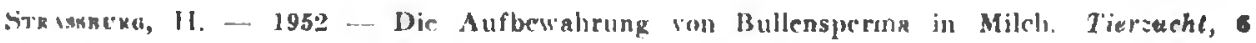
(i) $: 188$

Simasos, F. W. - Brakmi, J1. J. - 1951 - An cosin-nigrusin stain for differentinting live Hnd dead Iovine spermutomos. J. Animal Sci, 10( $(4): 981 / \tau$

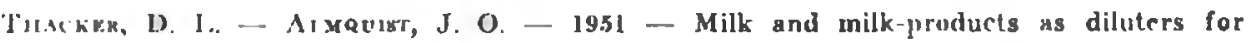
bovine sence. "in" J. Animal sci., 10(4):1082

'l'ияскк, J). L. -- Armutist, J. (). - 1953 - Diluters for bovine semen. I: Fertility and motility of bovine sperumtozon in hoiled milk. J. Lairy Sci, $36(2): 173 / 80$ 